\title{
Impactos das anomalias pluviais nas atividades agrícolas em Alagoa Nova e Lagoa Seca -
}

\section{Paraíba, Brasil}

Impacts of rainfall anomalies on agricultural activities in Alagoa Nova and Lagoa Seca - Paraíba, Brazil

Impactos de las anomalías pluviométricas en las actividades agrícolas en Alagoa Nova y Lagoa Seca -

Paraíba, Brasil

Raimundo Mainar de Medeiros ORCID: https://orcid.org/0000-0001-7361-1281 Universidade Federal Rural de Pernambuco, Brasil E-mail: mainarmedeiros@gmail.com

Luciano Marcelo Fallé Saboya ORCID: https://orcid.org/0000-0002-7586-6867 Universidade Federal de Campina Grande, Brasil E-mail: 1saboya@hotmail.com

Manoel Viera de França

ORCID: https://orcid.org/0000-0003-4973-9327 Universidade Federal Rural de Pernambuco, Brasil E-mail: manoelvieira.ufrpe@gmail.com

Romildo Morant de Holanda ORCID: https://orcid.org/0000-0001-7945-3616 Universidade Federal Rural de Pernambuco, Brasil E-mail: romildomorant@gmail.com

Moacyr Cunha Filho

ORCID: https://orcid.org/0000-0002-3466-8143 Universidade Federal Rural de Pernambuco, Brasil E-mail: Moacyr.cunhafo@ufrpe.br

Wagner Rodolfo de Araújo

ORCID: https://orcid.org/0000-0001-7203-0338 Universidade Estácio de Sá, Brasi E-mail:wagneraraujops@gmail.com

\section{Resumo}

O objetivo é caracterizar e analisar a anomalia pluviometria entre os municípios Alagoa Nova e Lagoa Seca entendendo as oscilações anômalas climática, com a provável influência e ocorrência dos fenômenos climáticos El Niño e La Niña, no setor da citricultura e hortifrút, sendo realizado o cálculo das anomalias pluviais. Utilizou-se dos totais anuais pluviais do período de 1983-2019 para os municípios de Lagoa Seca e Alagoa Nova - Paraíba e realizouse a classificação segundo a Intensidade dos fenômenos El Niño e La Niña, calculando sua anomalia anual levando em considerado as suas respectivas média. Todavia, não se descartar que na maioria dos anos com anomalias negativas ocorreram de forma igualadas à fenômenos La Niña e El Niño, o contrário pode ser registrado para o caso do El Niño que ocorreu anomalias negativa e na La Niña anomalias positivas ambos de intensidade aumentadas ou reduzidas. Portanto, nada se pode afirmar que nas regiões estudada os fenômenos ENOS não influenciaram nos seus índices pluviais locais, e que o ENOS não é o principal elemento climático e/ou ambiental os quais contribui para a ocorrência de eventos extremos pluviais. Sendo necessário buscar avaliar outros fenômenos climáticos e o perfil ambiental regional visando justificar a variabilidade pluvial. A influência dos fatores locais na distribuição espacial da chuva é evidente nos gráficos de El Nina e La Nina, destacados pelas anomalias. A concentração pluviométrica é devida aos fatores controladores favoráveis, relevo, aproximação do planalto da Borborema e a vegetação. Os acumulados mais baixos foram ocasionados pelo resfriamento do atlântico tropical e os bloqueios nos sistemas locais e regionais.

Palavras-chave: Variabilidade Climática; Agropecuária; Estabilidade ou Instabilidade Pluvial.

\footnotetext{
Abstract

The objective is to characterize and analyze the anomalous rainfall between the municipalities of Alagoa Nova and Lagoa Seca, understanding the anomalous climate oscillations, with the probable influence and occurrence of El Niño and La Niña climate phenomena, in the citrus and horticulture sector, and the calculation of rainfall anomalies. We used the total annual rainfall for the period 1983-2019 for the municipalities of Lagoa Seca and Alagoa Nova -
} 
Paraíba and performed the classification according to the intensity of El Niño and La Niña phenomena, calculating their annual anomaly taking into account their respective averages. However, do not rule out that in most years with negative anomalies occurred so equal to La Niña and El Niño phenomena, the opposite can be registered for the case of El Niño that occurred negative anomalies and La Niña positive anomalies both of increased or reduced intensity. Therefore, it can not be said that ENSO has not influenced the local rainfall in the regions studied, and that ENSO is not the main climatic and/or environmental element contributing to the occurrence of extreme rainfall events. It is necessary to evaluate other climatic phenomena and the regional environmental profile in order to justify the rainfall variability. The influence of local factors on the spatial distribution of rainfall is evident in the El Nina and La Nina graphs, highlighted by the anomalies. The rainfall concentration is due to the favorable controlling factors, relief, approach to the Borborema plateau and the vegetation. The lower accumulations were caused by the cooling of the tropical Atlantic and the blockages in the local and regional systems.

Keywords: Climatic variability; Agriculture; Stability or Rainfall Instability.

\section{Resumen}

El objetivo es caracterizar y analizar la anomalía pluvial entre los municipios Alagoa Nova y Lagoa Seca comprendiendo las oscilaciones climáticas anómalas, con la probable influencia y ocurrencia de los fenómenos climáticos El Niño y La Niña, en el sector citrícola y hortícola, realizándose el cálculo de las anomalías pluviales. Se utilizaron las precipitaciones totales anuales del período 1983-2019 para los municipios de Lagoa Seca y Alagoa Nova - Paraíba y se realizó la clasificación según la intensidad de los fenómenos de El Niño y La Niña, calculando su anomalía anual teniendo en cuenta su respectiva media. Sin embargo, no hay que descartar que en la mayoría de los años con anomalías negativas se produzcan de la misma manera a los fenómenos de La Niña y El Niño, lo contrario se puede registrar para el caso de El Niño que se produjeron anomalías negativas y La Niña anomalías positivas ambas de mayor o menor intensidad. Por lo tanto, no se puede afirmar que el ENSO no haya influido en los índices pluviométricos locales de las regiones estudiadas, y que el ENSO no sea el principal elemento climático y/o ambiental que contribuye a la aparición de eventos pluviométricos extremos. Es necesario evaluar otros fenómenos climáticos y el perfil ambiental regional para justificar la variabilidad de las precipitaciones. La influencia de los factores locales en la distribución espacial de las precipitaciones es evidente en los gráficos de El Niño y La Niña, resaltados por las anomalías. La concentración de las precipitaciones se debe a los factores de control favorables, el relieve, la aproximación de la meseta de Borborema y la vegetación. Las menores acumulaciones fueron causadas por el enfriamiento del Atlántico tropical y los bloqueos en los sistemas locales y regionales.

Palabras clave: Variabilidade Climática; Agropecuária; Estabilidade ou Instabilidade Pluvial.

\section{Introdução}

O fenômeno El Niño - Oscilação Sul (ENOS) é marcado por anomalias, positivas (El Niño) ou negativas (La Niña), de temperatura da superfície do mar no oceano Pacifico Tropical TSM). Múltiplos estudos vêm investigando a analogia do fenômeno ENOS com a variabilidade climática, principalmente a precipitação, em diversas regiões do Globo: (De Bodas et al., 2018; Matzenauter 2017; ARaújo et al., 2013) entre tantos outros. O conhecimento da influência do ENOS na pluviometria de uma região possibilita esquematizar estratégias para lidar com o risco associado a variabilidade climática na agricultura, economia e ambiente, contribuindo com maior estabilidade socioeconômica das sociedades, ou mesmo para os governos.

Na região tropical a circulação atmosférica é profundamente afetada pelos padrões termodinâmicos das bacias dos Oceanos Pacífico e Atlântico tropicais. Em anos com anomalias positivas e/ou negativas da Temperatura da Superfície desses oceanos, influenciando no significado dos sentidos latitudinal, e a célula de Walker, que opera no sentido longitudinal, onde as perturbações vem provocando anomalias na circulação atmosférica sobre os trópicos.

A chuva é a principal forma de entrada da água no ciclo hidrológico, sendo um fenômeno climático com a importância de manter as fontes de água e usado para certas atividades humanas, como agricultura e pesca (Molina et al., 2014). A caracterização dos eventos chuvosos determina os seus parâmetros (intensidade, tempo de recorrência, duração e altura chuvosa) e na análise da distribuição desses parâmetros no tempo e no espaço (Depiné et al., 2014). A precipitação é um fenômeno natural complexo que se caracteriza por uma significativa variabilidade temporal e espacial, embora as observações em superfície forneçam registros, as densidades da maioria das redes pluviométricas podem não capturar a variabilidade 
espacial da precipitação em muitas regiões do mundo, principalmente em países em desenvolvimento e em áreas remotas (YAN 2018).

O fenômeno da variabilidade pluvial no Nordeste, especialmente os eventos de seca, além do ponto de vista climatológico, assume uma perspectiva social e econômica, com consequências que afetam o abastecimento da população, a agricultura, pecuária e aumentam o desemprego (MArengo et al., 2011; Marengo; Cunha \& Alves, 2016). Assim, a questão da água deve ser tratada levando em consideração a relação entre os recursos hídricos com as características ambientais, sociais e culturais locais, visando, além da conservação, a qualidade de vida da população e o desenvolvimento socioeconômico (Rebouças, 1997).

Silva et al, (2016) avaliaram a flutuação da precipitação no município de Alagoa Nova, em anos de ocorrência do El Niño, corresponderam à série de 1976-2010. As flutuações entre os anos estudados com El Niño em atividade foram de normal a muito seco. Os meses de junho de 1980 as chuvas foram reduzidas 67,3\%. No ano de 1993 as chuvas ocorreram entre a normalidade. Nos meses de abril a agosto de 1998 sofreram reduções com variações de 32,9 a 81\%, nos meses de maio e julho de 2010 ocorreram exceções na variabilidade da chuva.

No semiárido nordestino, a precipitação se distribui de forma irregular temporal e espacialmente, com longos períodos de estiagem. As temperaturas apresentam médias elevadas e, consequentemente, o potencial para a evaporação é alto (Clemente, 2021; Marengo, 2008). Nesta região, a precipitação é resultado da dinâmica atmosférica, sendo influenciada ainda por fatores locais, como o relevo e a posição geográfica (Marengo et al, 2011).

O aquecimento anômalo das águas do Oceano Pacífico Equatorial vem modificando a dinâmica normal da Célula de Walker (MENDONÇA et al., 2007), ocasionando modificações nos regimes pluviais (Grimm et al., 2000), causando eventos extremos de chuvas sobre a América do Sul (Grimm et al., 2009), assim como provocando variações climáticos, na temperatura; a qual modifica o padrão pluvial na região tropical, principalmente entre junho e dezembro, com um aumento expressivo da precipitação ocorrente no Pacífico Tropical Central e Oriental, em oposição às chuvas abaixo da média nas regiões da Indonésia e Pacífico Tropical Ocidental, resultando em situação de seca e favorecendo a emersão de queimadas (Oliveira, 1999).

No Brasil quando se registra atividades do El Niño, observa-se um decréscimo pluvial em algumas áreas da região Nordeste, na região Sul há chuvas acima do normal, apresentando uma primavera mais chuvosa (Cunha et al., 2011).

FAO (2021) destaca que o rápido crescimento das cidades vem tendo um impacto significativo sobre a terra e os recursos hídricos, invadindo terras agrícolas de boa qualidade. O documento refere ainda que a agricultura de sequeiro produz $60 \%$ dos alimentos do mundo, ocupando $80 \%$ das terras cultivadas. Já a irrigada produz $40 \%$ em $20 \%$ da terra. Outra questão destacada no relatório é o impacto da erosão do solo, que arrasta entre 20 e 37 bilhões de toneladas da camada superior do recurso anualmente. Esta situação reduz o rendimento das lavouras e a capacidade do solo de armazenar e reciclar carbono, nutrientes e água. As perdas anuais observadas na produção de cereais devido à erosão são estimadas em 7,6 milhões de toneladas.

O comportamento adequado dos setores agrícolas e da avicultura depende sobremaneira de condições climáticas e ambientais adaptadas (Araújo et al., 2013). A agricultura nordestina em sua grande parte se caracteriza pelo sistema de produção em sequeiro, assim como o setor avícola do Nordeste, onde o desenvolvimento das culturas depende quase que exclusivamente do regime de distribuição pluvial. Silva et al., (2009) mostraram que o problema da irregularidade pluviométrica do Nordeste do Brasil resulta não só da variação dos totais pluviais, mas, também da sua duração e intensidade.

Os modelos Agro meteorológico e a interpretação de dados climáticos relacionados com o crescimento, desenvolvimento e produtividade das culturas fornecem informações que permitem ao setor agrícola tomar importantes 
decisões, tais como: melhor planejamento do uso do solo, adaptação de culturas, monitoramento e previsão de safras, controle de pragas e doenças estratégias de pesquisa e planejamento (Lazinski, 1993).

Relacionado a estas questões Tucci (2000) destaca a funcionalidade do ciclo hidrológico, que se refere a um fenômeno global de circulação da água. Este ciclo está atrelado ao intercâmbio entre as movimentações d'água na superfície terrestre e da atmosfera, impulsionado basicamente pela energia solar associada à gravidade e à rotação terrestre. $\mathrm{O}$ ciclo hidrológico é normalmente estudado com maior interesse na fase terrestre, onde o recorte espacial mais utilizado são os lençóis d'águas a céu aberto, rios e bacia hidrográfica, assim como na determinação dos intervalos de irrigação, na previsão da produtividade agrícola, na classificação climática, entre outras várias atividades, envolvendo o manejo e o planejamento dos recursos hídricos.

O objetivo é caracterizar e analisar a anomalia pluviometria entre os municípios Alagoa Nova e Lagoa Seca entendendo as oscilações anômalas climática, com a provável influência e ocorrência dos fenômenos climáticos El Niño e La Niña, no setor da citricultura e hortifruti, sendo realizado o cálculo das anomalias sob análise do período de 56 anos (1963 a 2019).

\section{Material e Método}

O município de Alagoa Nova está localizado na Microrregião Alagoa Nova e na Mesorregião Agreste Paraibano do Estado da Paraíba. Sua Área é de $122 \mathrm{~km}^{2}$ representando $0.2166 \%$ do Estado, $0.0079 \%$ da Região e $0.0014 \%$ de todo o território brasileiro. A sede do município tem uma altitude aproximada de 530 metros distando $98,8123 \mathrm{Km}$ da capital. O acesso é feito, a partir de João Pessoa, pelas rodovias BR 239/BR 104/PB 097.

A área da unidade é recortada por rios perenes, porém de pequena vazão e o potencial de água subterrânea é baixo. A vegetação desta unidade é formada por Florestas Subcaducifólica e Caducifólica, próprias das áreas agrestes. O clima é do tipo Tropical Chuvoso, com verão seco. A estação chuvosa se inicia em janeiro/fevereiro com término em setembro, podendo se adiantar até outubro.

Lagoa Seca posiciona-se na Microrregião Lagoa Seco e na Mesorregião Agreste Paraibano. Com área territorial de $109 \mathrm{~km}^{2}$ representando 0,1937\% do Estado, 0,007\% da Região Nordeste e 0,0013\% do território brasileiro (Figura 1). A parte sul do município de Lagoa Seca encontra-se inserida nas áreas da bacia hidrográfica do rio Paraíba, região do Baixo Paraíba, sendo o seu principal curso d'água o riacho Marinho. Nas partes norte e leste encontram-se inserida na bacia do rio Mamanguape, cujo principal curso d'água é o próprio rio. Todos os cursos d'água d'área estudada têm regime de fluxo intermitente e o padrão da drenagem é do tipo dendrítico. A cidade é limitada pelos municípios de Campina Grande, Massaranduba, Matinhas, São Sebastião de Lagoa de Roça, Montadas, Puxinanã. A sede municipal encontra-se posicionada na Latitude $07^{\circ} 10^{\prime} 15^{\prime \prime}$ sul; Longitude $35^{\circ} 51^{\prime} 13^{\prime \prime}$ a oeste de Greenwich com altitude de 634 metros. 
Figura 1. Localização dos municípios Lagoa Seca e Alagoa Nova no estado da Paraíba.

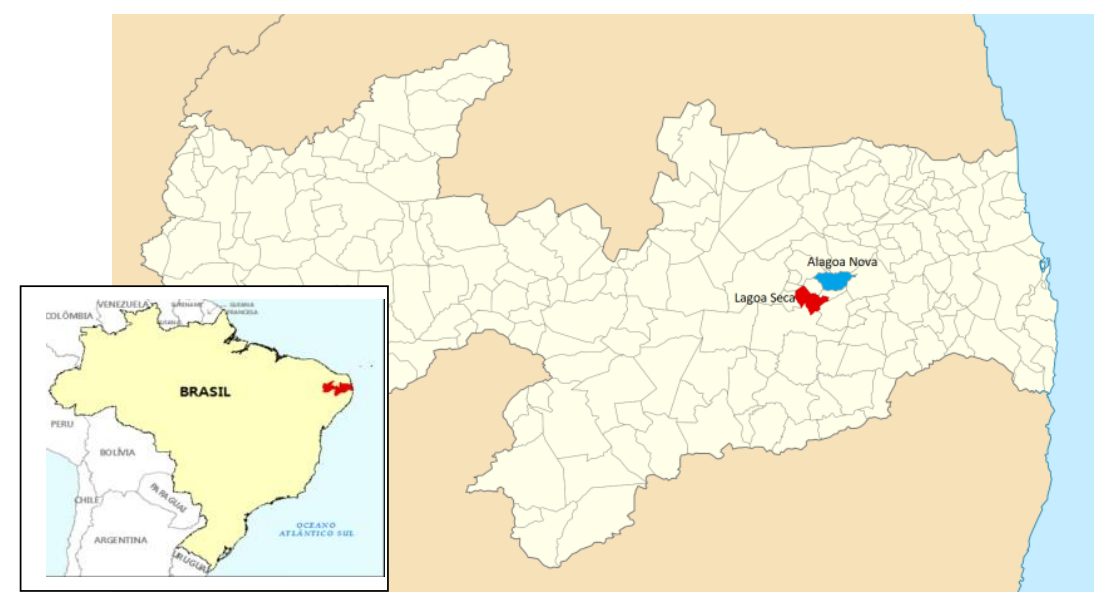

Fonte: Saboya (2022).

Utilizou-se dos totais anuais pluviais do período de 1963-2019 para os municípios de Lagoa Seca e Alagoa Nova Paraíba e realizou-se a classificação segundo a Intensidade dos fenômenos El Niño e La Niña, calculando sua anomalia anual levando em considerado as suas respectivas média.

Na Tabela 1 tem-se os demonstrativos dos índices pluviais em ocorrências do El Niño e La Niña, sua intensidade e classificação entre os anos de 1963-2019

Tabela 1. Classificação e Intensidade dos fenômenos El Niño La Niña entre os anos de 1963 a 2019.

\begin{tabular}{|l|l|l|l|l|l|}
\hline Ano & Classificação & Intensidade & Ano & Classificação & Intensidade \\
\hline 1982 & El Niño & Forte & 2001 & La Niña & Moderada \\
\hline 1983 & El Niño & Forte & 2002 & El Niño & Moderado \\
\hline 1984 & La Niña & Fraca & 2003 & El Niño & Moderado \\
\hline 1985 & La Niña & Fraca & 2004 & El Niño & Forte \\
\hline 1986 & El Niño & Moderado & 2005 & El Niño & Forte \\
\hline 1987 & El Niño & Moderado & 2006 & El Niño & Forte \\
\hline 1988 & El Niño & Moderado & 2007 & El Niño & Forte \\
\hline 1989 & La Niña & Forte & 2008 & La Niña & Forte \\
\hline 1990 & El Niño & Forte & 2009 & El Niño & Fraco \\
\hline 1991 & El Niño & Forte & 2010 & El Niño & Fraco \\
\hline 1992 & El Niño & Forte & 2011 & La Niña & Moderada \\
\hline 1993 & El Niño & Forte & 2012 & El Niño & Moderado \\
\hline 1994 & El Niño & Moderado & 2013 & El Niño & Forte \\
\hline 1995 & El Niño & Moderado & 2014 & La Niña & Neutra \\
\hline 1996 & La Niña & Fraca & 2015 & El Niño & Forte \\
\hline 1997 & El Niño & Forte & 2016 & El Niño & Forte \\
\hline 1998 & La Niña & Moderada & 2017 & La Niña & Moderada \\
\hline 1999 & La Niña & Moderada & 2018 & El Niño & Moderado \\
\hline 2000 & La Niña & Moderada & 2019 & El Niño & Forte \\
\hline
\end{tabular}

Fonte: Medeiros (2022).

\section{Resultados e Discussões}

Segundo Medeiros et al., (2013) as maiores taxas de precipitação em La Niña são devidas as tendências de precipitação que o mesmo apresenta acima da média, em comparação com períodos de El Niño, que podem apresentar redução entre 60 e $65 \%$ no índice pluvial. 
O conhecimento do período chuvoso permite a identificação da melhor época para plantar e colher com redução do risco de perda da produção por falta de água (Azevedo et al., 2007). O comportamento anual da precipitação determina se a cultura se desenvolverá ou se sofrerá déficit hídrico (Silva et al, 2011). Sobre a prática da agricultura no semiárido, Marengo (2008) relata que o comportamento irregular da precipitação é um obstáculo e que esta atividade é vulnerável à seca.

Na Figura 2 tem-se as distribuições das anomalias anuais negativas período de La Niña nos municípios Alagoa Nova e Lagoa Seca - Paraíba

Eventos climáticos mais comuns estão associados a flutuações pluviais na região Nordeste, segundo Nóbrega et al. (2016), os eventos com mais potencial para os quais influenciarem são as oscilações na Temperatura da Superfície do Mar, sendo o fenômeno El Niño-Oscilação Sul (ENOS) caracterizado por anomalias no Oceano Pacífico. Cirino et al. (2015) comenta que o El Niño está associado a registros de chuvas abaixo da média, enquanto que a La Niña a chuvas acima durante seus eventos. Todavia, tal correlação é considerada não unívoca pois diversas outras pesquisas mostram que eventos extremos de precipitação não ocorreram simultaneamente com os fenômenos supracitados (Freire et al., 2011).

No ano de 1984 observam-se a oscilação das anomalias para os municípios de Alagoa Nova e Lagoa Seca. Vemos que a intensidade das anomalias positivas foi mais intensa para o município de Alagoa Nova, exceto no mês de março que registrou anomalia negativa e abril sendo um pouco abaixo.

Para o ano de 1985 destaca-se anomalias negativas nos meses de junho para os dois municípios e nos meses de agosto a setembro para Lagoa Seca. Observando-se a variabilidade das anomalias positivas destaca Alagoa Nova com suas flutuações anômalas maiores que as de Lagoa Seca exceto o mês de abril.

O ano de 1989 chama nossa atenção para o predomínio das intensidades anômalas negativa na área de estudo. As anomalias positivas irregulares ocorridas nos meses março, maio e setembro (Alagoa Nova) e para os meses de abril, novembro e dezembro (Lagoa Seca).

Figura 2. Distribuições das anomalias anuais negativas e positivas do período de La Niña nos municípios Alagoa Nova e Lagoa Seca - Paraíba, para 1984; 1985 e 1989.

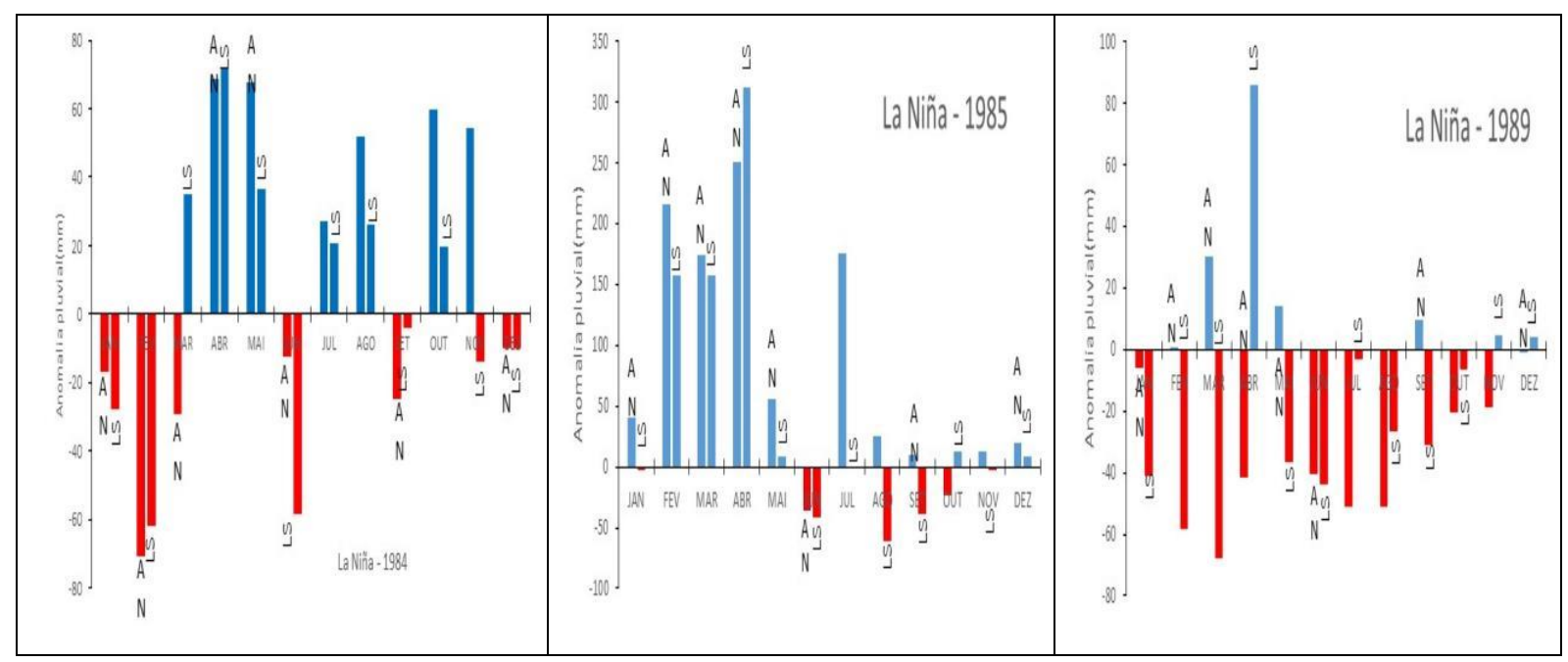

Fonte: Medeiros (2022).

Em 1995 registrou-se anomalias positivas para os meses de maio, junho, julho, e novembro em Alagoa Nova, e nos meses de junho, julho em Lagoa Seca. As flutuações das anomalias positivas para ambos os municípios em estudos oscilaram de $18 \mathrm{~mm}$ a $72 \mathrm{~mm}$. As anomalias negativas predominaram em seis meses para os dois municípios e nos meses de maio, agosto, 
setembro a dezembro em Lagoa seca e entre agosto e outubro em Alagoa Nova. Tais flutuabilidades estão em similaridades com o estudo de França et al, (2021). E os resultados discutidos sobre a variabilidade pluviais corroboram com os estudos de Marengo et al, (2011).

As predominâncias de anomalias negativas para o município de Alagoa Nova (AN) foram para os meses de janeiro, junho a agosto, as mesmas anomalias negativas ocorreram nos meses de fevereiro, março maio a julho e dezembro em Lagoa Seca (LS). Destacam-se que mesmo períodos de La Niña as variabilidades das anomalias ocasionam chuvas acima dos normais como pode ser detectado para o ano de 1966.

O ano de 1998 só ocorreu anomalias pluviais positivas nos meses de agosto, outubro e dezembro. Para os restantes dos meses estas flutuabilidades anômalas foram negativas e de alta variabilidade, tais oscilações pluviais corroboram com os resultados dos estudos de Marengo et al, (2007).

Figura 3. Distribuições das anomalias anuais negativas e positivas do período de La Niña nos municípios Alagoa Nova e Lagoa Seca - Paraíba, para 1995; 1996 e 1998.

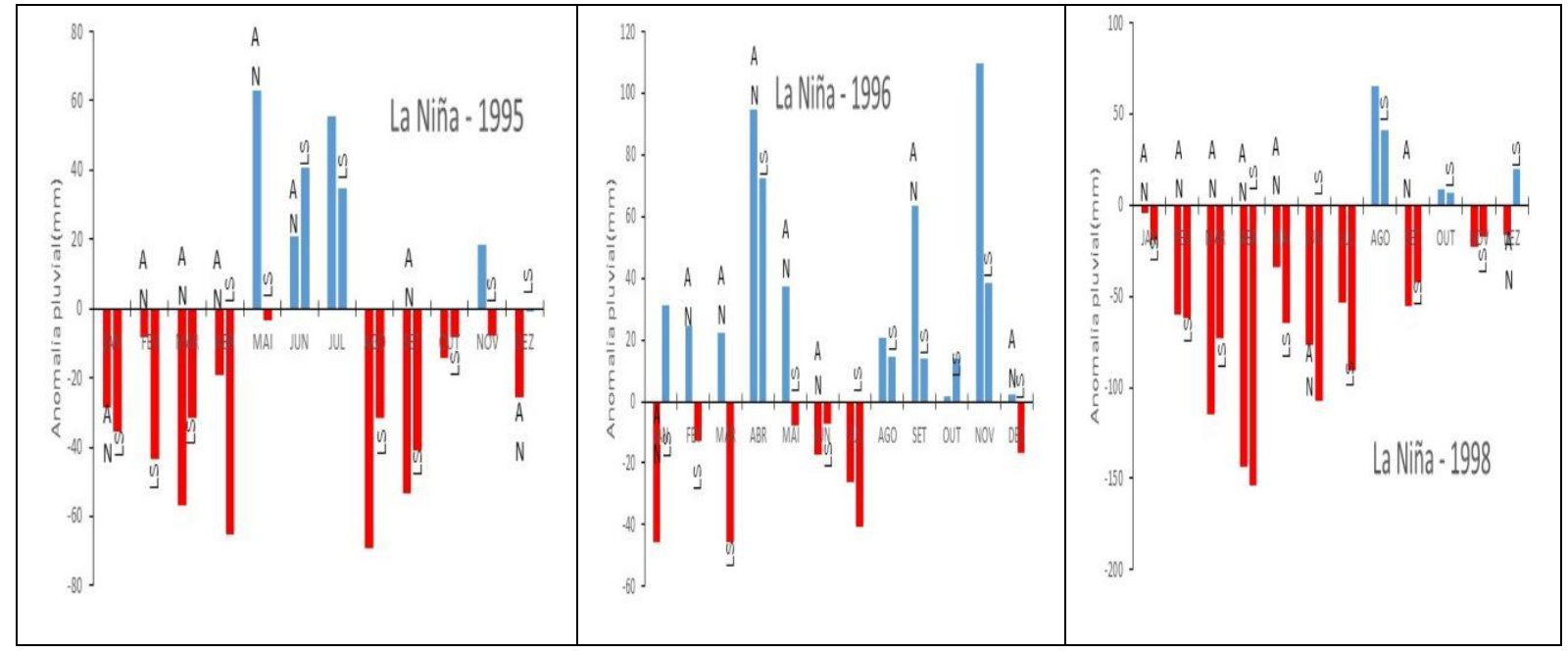

Fonte: Medeiros (2022).

Com anomalias negativas registradas nos meses abril a setembro para os dois municípios (LS; AN) e os meses de novembro; janeiro e fevereiros para Alagoa Nova com forte a moderadas anomalias. A predominância positiva ocorreu nos demais meses com flutuação moderada para o ano de 1999.

O ano 2000 predominou anomalias pluvial positiva na sua grande maioria dos meses, as oscilações positivas fluíram de 7,5 mm a $175 \mathrm{~mm}$, observam-se que a anomalia negativa de media a baixa oscilações ocorreram nos meses de março; maio e outubro (LS; AN) e novembro e dezembro (AN).

As irregularidades anômalas observadas nas anomalias do ano de 2001 vem a corroborar com os estudos de Marengo et al, (2007) Marengo et al, (2008) e Marengo et al, (2011). 
Figura 4. Distribuições das anomalias anuais negativas e positivas do período de La Niña nos municípios Alagoa Nova e Lagoa Seca - Paraíba, para 1999, 2000 e 2001.

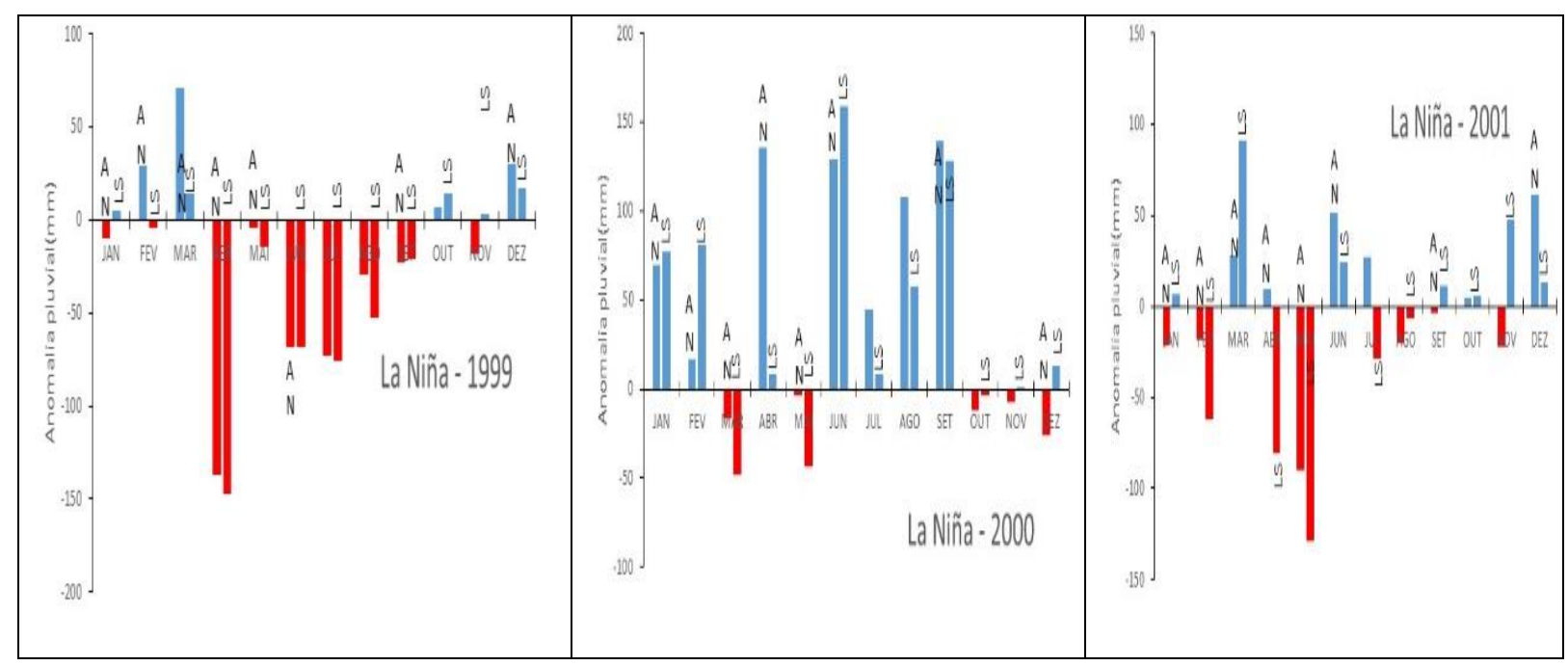

Fonte: Medeiros (2022).

Para 2007 observam-se as distribuições das anomalias pluviais dos municípios Lagoa Seca (LS) e Alagoa Nova (NA). As variabilidades anômalas positivas registraram-se em Alagoa Nova nos meses de junho e setembro e em Lagoa seca junho, agosto e setembro com oscilações moderadas a fraca para ambos os municípios estudado. As anomalias negativas predominaram nos restantes dos meses e sua variabilidade foram de moderadas a intensas. Estas oscilações corroboram com o estudo de França et al, (2021).

O ano de 2008 foi caracterizado por variabilidades anômalas negativas e positivas com flutuabilidades modera a forte para ambas as áreas de estudo. As oscilações positivas anômalas registraram-se nos meses de março, julho (LS; AN); Maio, agosto (NA); setembro (LS). As variabilidades negativas predominaram no restante dos demais meses, estas variabilidades vêm a corroborar com o estudo de Medeiros et al, (2021).

As oscilações anômalas irregulares da pluviometria para o ano de 2009 em fase do episódio La Niña registaram anomalias positivas para Alagoa nova nos meses de janeiro, junho e outubro. No município de Lagoa Seca as anomalias positivas ocorreram nos meses de fevereiro, abril, junho a outubro. As anomalias negativas ocorreram nos restantes dos meses do ano em estudo. As flutuações anômalas negativas fluíram de $-275 \mathrm{~mm}$ a $10 \mathrm{~mm}$ e as anomalias positivas oscilaram de 15 $\mathrm{mm}$ a $110 \mathrm{~mm}$. 
Figura 5. Distribuições das anomalias anuais negativas e positivas do período de La Niña nos municípios Alagoa Nova e Lagoa Seca - Paraíba, para 2007, 2008 e 2009.

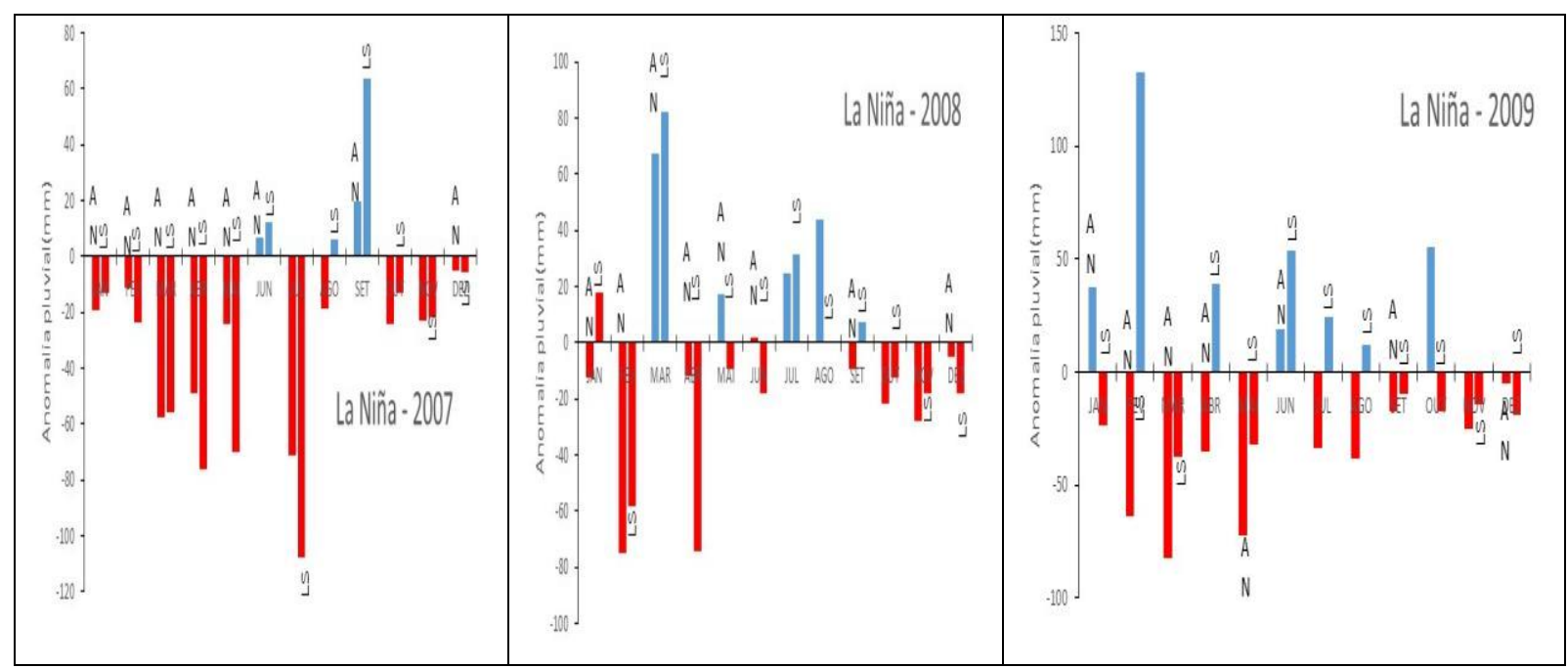

Fonte: Medeiros (2022).

O ano de 2011 caracterizado por período de La Niña Moderada registrou anomalias de baixas intensidades tantos positivas como negativas, destacando que Alagoa Nova ocorreu as maiores concentrações das anomalias negativas e para Lagoa Seca as anomalias positivas, mesmo assim foi um ano de chuvas abaixo do normal para a área estudada.

Figura 6. Distribuições das anomalias anuais negativas e positivas do período de La Niña nos municípios Alagoa Nova e Lagoa Seca - Paraíba, para 2011.

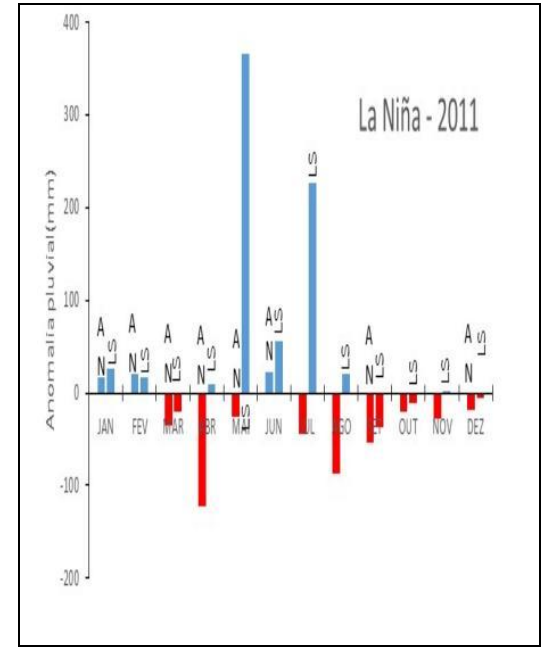

Fonte: Medeiros (2022).

Silva et al, (2017) estudaram as oscilações pluviais sobre a atuação do episódio climático El Niño e La Niña em relação aos índices pluviométricos no município de São Bento do Una - PE o qual vem enfrentando a crise hídrica nos dias atuais. Os autores constataram interferência antrópica na atual situação de seca da região, maiores estudos em fenômenos de 
larga escala que são necessários para a identificação dos fatores antrópicos, e dessa forma propor soluções para a seca no município.

Na Figura 3 tem-se as distribuições das anomalias anuais positivas e negativas no período de El Niño nos municípios Alagoa Nova e Lagoa Seca - Paraíba.

A distribuição da anomalia sobre a atuação do El Niño no ano de 1981 para os municípios Alagoa Nova (NA) e Lagoa seca foram irregulares e de amplitudes diferencias, destacamos as anomalias positivas que fluíram de $10 \mathrm{~mm}$ a $300 \mathrm{~mm}$ e as anomalias negativas com flutuações oscilando de $-28 \mathrm{~mm}$ a $-132 \mathrm{~mm}$, ambas as anomalias tiveram suas representações por igual distribuição mensal sendo NA a de maior variabilidade positiva e LS nas negativas. Tais variabilidades vêm a corroborar com o estudo de França et al, (2021).

Os anos de 1982 e 1983 tem similaridades nas irregularidades anômalas, como se pode observar as intensidades de suas variabilidades são maiores nas anomalias negativas e as anomalias positivas são irregulares, destaca ainda as anomalias positivas para o ano de 1989 entre os meses de agosto a novembro, estas flutuações tem similaridades com os estudos de Marengo et al, (2011) para a distribuição pluvial. Os índices pluviais não foram necessários para contribuir com a citricultura e hortifruti da região.

Figura 7. Distribuições das anomalias anuais positivas e negativas no período de El Niño nos municípios Alagoa Nova e Lagoa Seca - Paraíba. 1981; 1982 e 1983.

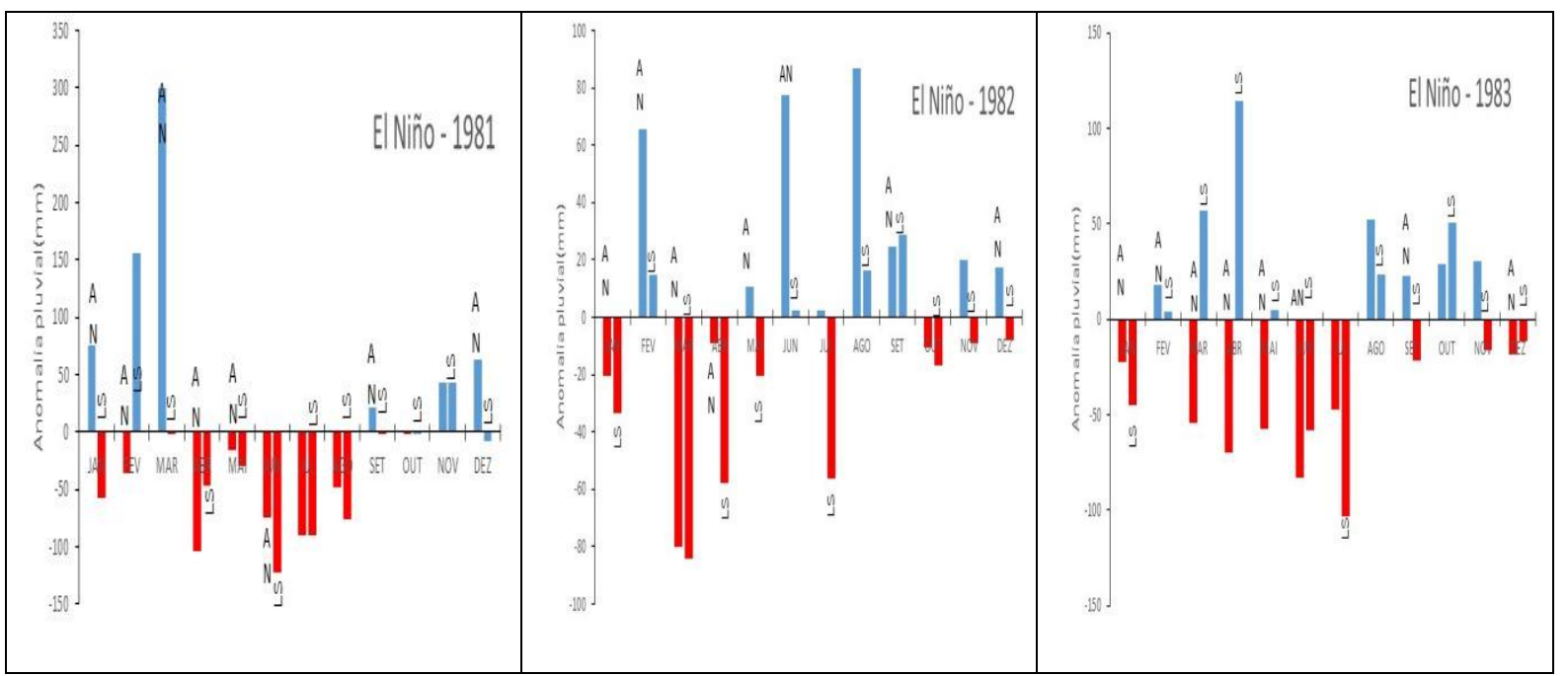

Fonte: Medeiros (2022).

O ano de 1986 regido pela variabilidade do El Niño registrou anomalias positivas nos meses de fevereiro a dezembro com oscilações fluindo de $5 \mathrm{~mm}$ a $150 \mathrm{~mm}$ (NA) e de $5 \mathrm{~mm}$ a $140 \mathrm{~mm}$ (LS) excetos os meses de janeiro (AN; LS), junho e setembro em Lagoa seca, destacam-se que mesmo em período de El Niño as chuvas auxiliaram a citricultura e hortifruti nas áreas de estudos, estes resultados vem a corroboram com os encontrados por França et al, (2021).

Os anos de 1987 e 1988 predominaram o episódio El Niño Moderado, registrando anomalias irregulares e reduzindo seus índices pluviais para a hortifruti e citricultura, nos referidos anos a predominância da anomalia negativa foi mais intensa que a normalidade, mesmo ocorrendo anomalias positivas, estas variabilidades estão em conformidades com os estudos de Marengo et al, (2007); Marengo et al., (2011) e Medeiros et al., (2021). 
Figura 8. Distribuições das anomalias anuais positivas e negativas no período de El Niño nos municípios Alagoa Nova e Lagoa Seca - Paraíba. 1986; 1987 e 1988.

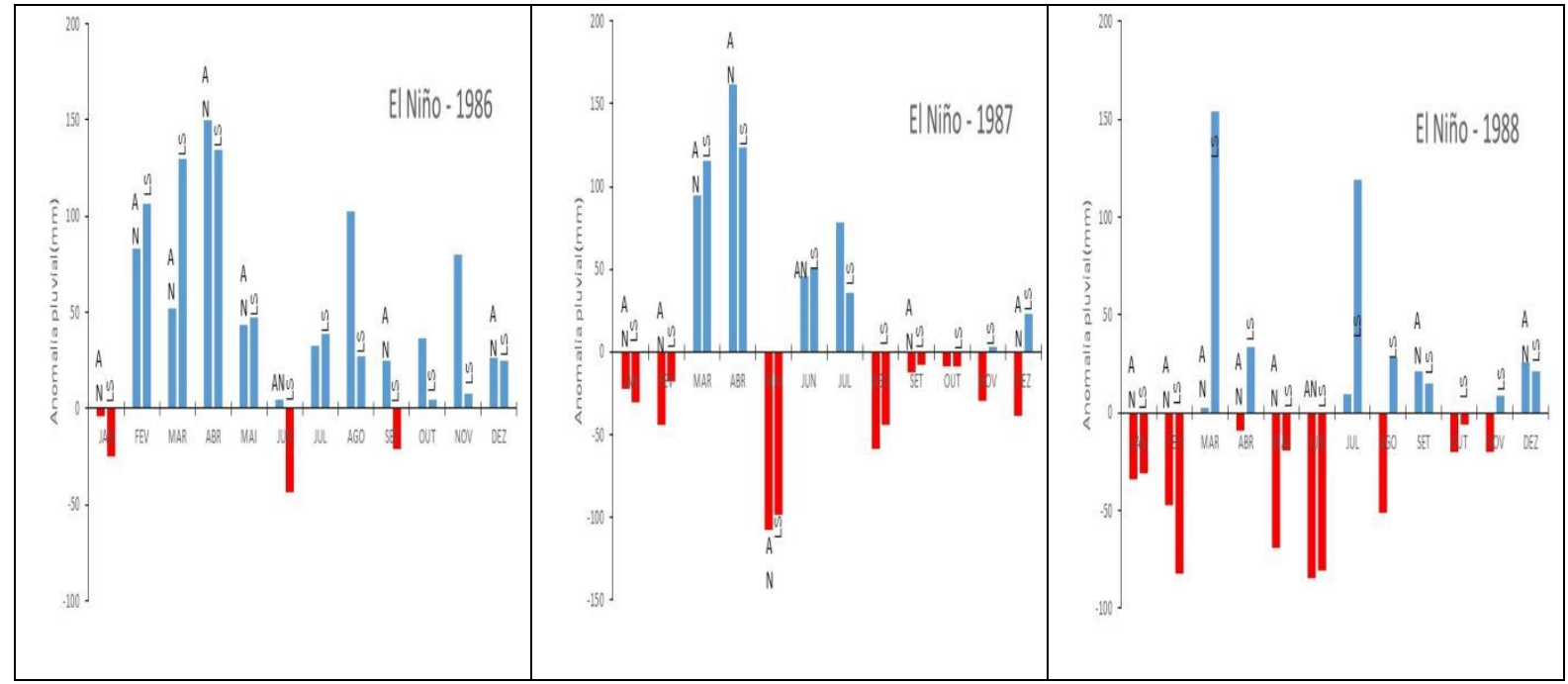

Fonte: Medeiros (2022).

Com oscilações irregulares e de moderada a forte intensidade de anomalias (positivas e negativas) no período de El Niño nos municípios Alagoa Nova e Lagoa Seca - Paraíba. 1990; 1991 e 1992, ocasionado baixa contribuições a hortifruti e citricultura dos municípios estudados. Observando os três anos destacamos que o ano de 1991 foi o de melhores condições de anomalias positivas para a área. Este resultado vem a corrobora com os estudos de França et al, (2021).

Figura 9. Distribuições das anomalias anuais positivas e negativas no período de El Niño nos municípios Alagoa Nova e Lagoa Seca - Paraíba. 1990; 1991 e 1992.

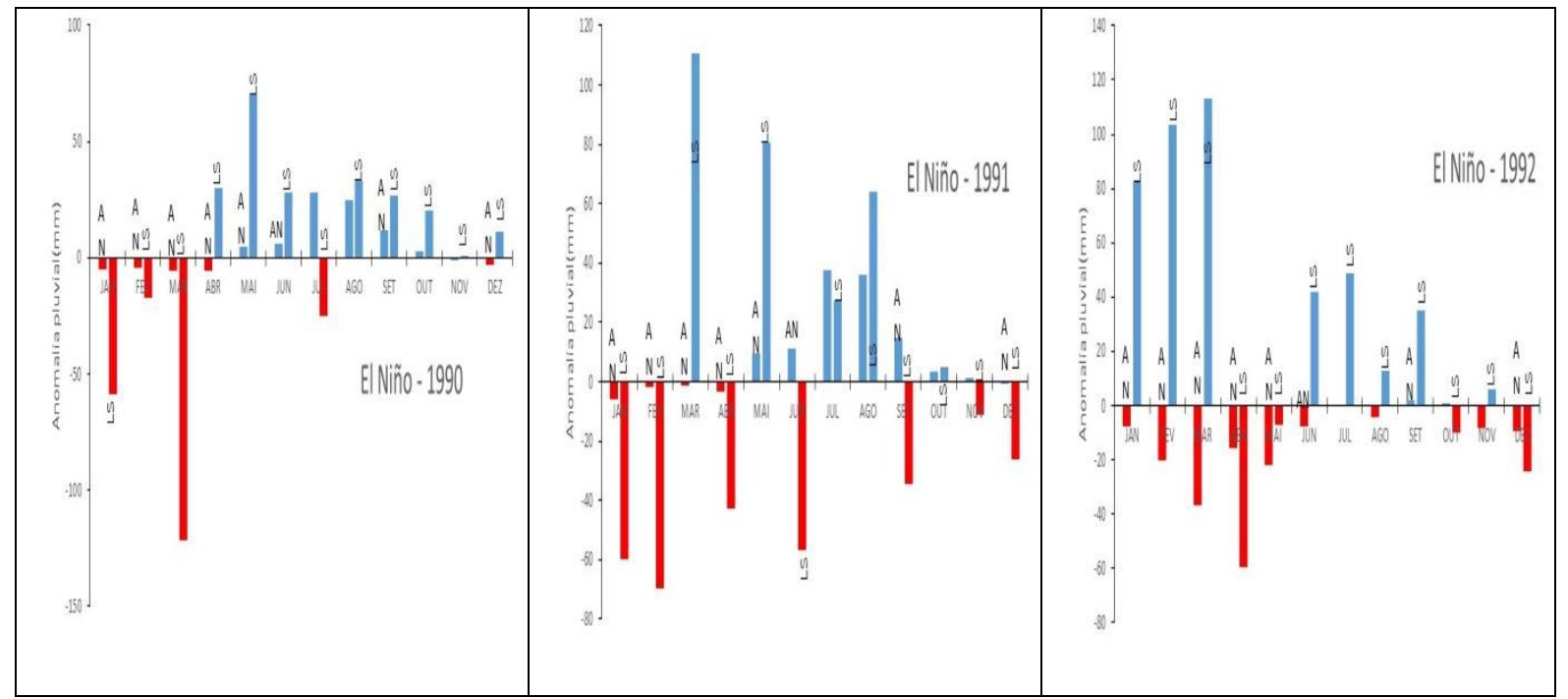

Fonte: Medeiros (2022).

O ano de 1993 caracterizado por um ano de El Niño forte registrou anomalias positivas para os meses de maio a outubro em Alagoa nova (AN) e em outubro para o município de Lagoa Seca (LS), com oscilações de 5 mm a 32,1 mm. As anomalias negativas predominaram nos restantes dos meses do ano com flutuações $-85 \mathrm{~mm}$ a 3,5 mm. Os índices pluviais não foram necessários para contribuir com a citricultura e hortifruti da região. 
O ano de 1994 predominou o fenômeno de larga Escala El Niño de intensidade moderada e ocasionou anomalias positivas para os meses de março a julho, setembro e dezembro com oscilações moderadas de anomalias pluviais, os meses de janeiro, fevereiro, agosto, setembro e novembro registrou-se anomalias negativa oscilando de $-92 \mathrm{~mm}$ a $0,5 \mathrm{~mm}$, os índices pluviais contribuíram para os desenvolvimentos da hortifruti e pouca contribuição para citricultura da região. Resultados semelhantes foram encontrados por França et al, (2021).

Com predominância de El Niño forte no ano de 1997 ocorreram anomalias negativas de moderadas oscilações nos meses de janeiro, julho, setembro e novembro para os dois municípios em estudos e anomalias negativas para o município de Lagoa seca nos meses de março, agosto e outubro para Alagoa Nova.

Com variabilidades irregulares para os anos em estudos tanto as atuações do El Niño e La Niña registram índices pluviais irregulares ora contribuindo ou não para a citricultura e hortifruti da área em estudo. Segundo Marengo et al, (2008); Marengo et al, (2011) estás irregularidades pluviais são quase que constaste na região do Nordeste Brasileiro.

Figura 10. Distribuições das anomalias anuais positivas e negativas no período de El Niño nos municípios Alagoa Nova e Lagoa Seca - Paraíba. 1993; 1994 e 1997.

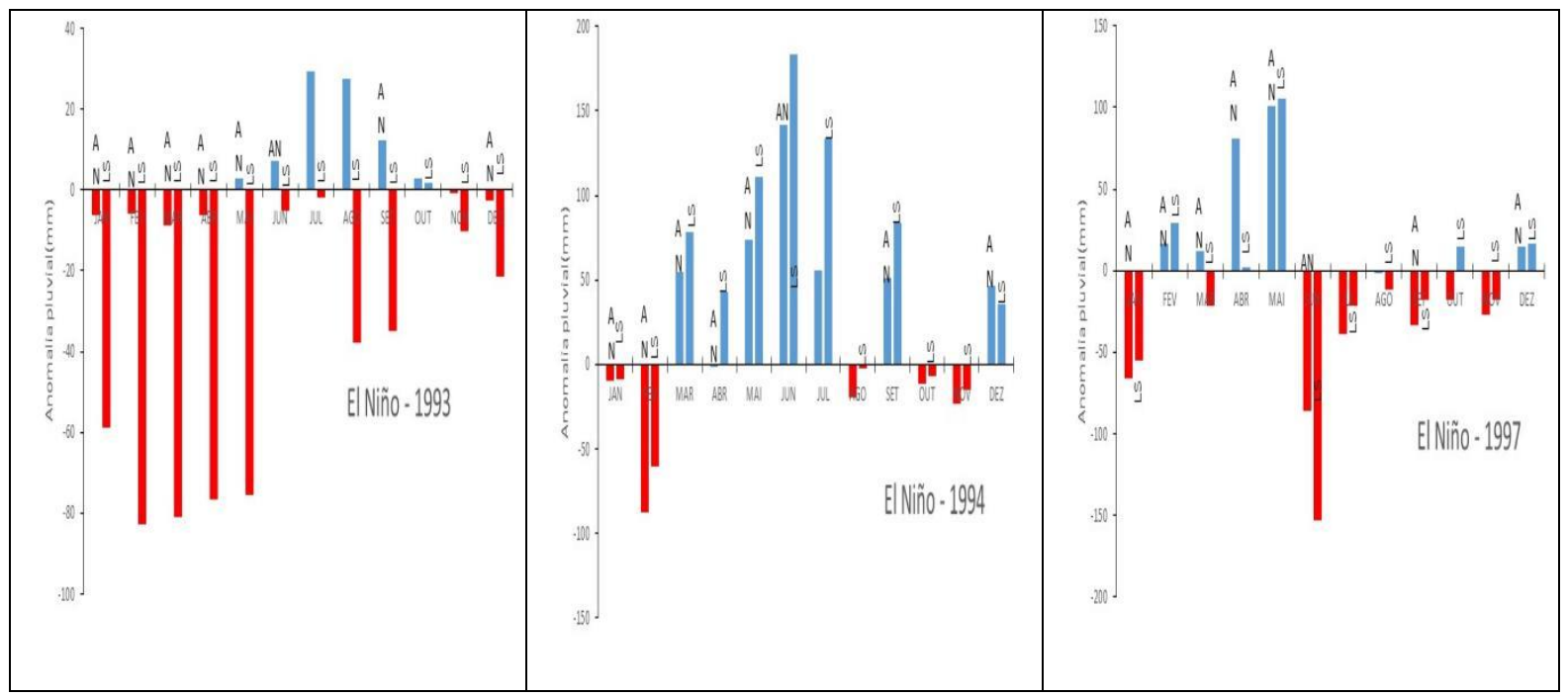

Fonte: Medeiros (2022).

2002 e 2003 foram classificados com anos de El Niño moderado e o ano de 2004 como El Niño forte, destacamos as irregularidades anômalas pluviais entre os referidos anos pode ou não oferecerem índices pluviais acima ou abaixo da média histórica e sua influência irão serem ocasionadas pelos sistemas atmosféricos de meso e larga escala seguidamente de suas contribuições locais e regionais, de acordo com os resultados de França et al, (2021) e Marengo et al (2016).

Observou-se que os efeitos do El Niño ou da La Niña na área de estudo poder sofrerem contribuições ou não nas oscilações dos índices pluviais para a hortifruti e citriculturas da região. 
Figura 11. Distribuições das anomalias anuais positivas e negativas no período de El Niño nos municípios Alagoa Nova e Lagoa Seca - Paraíba. 2002; 2003 e 2004.

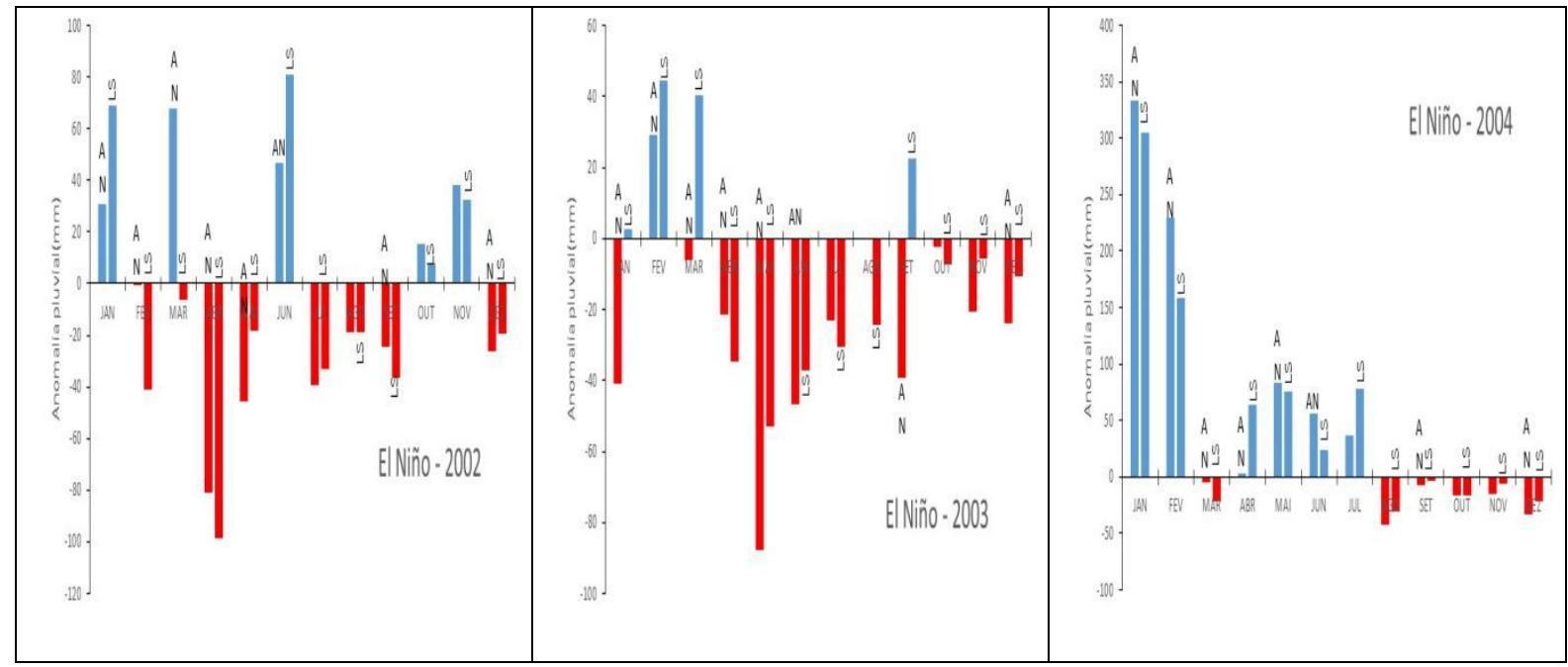

Fonte: Medeiros (2022).

As variabilidades anômalas positivas fracas ocorridas no ano de 2005 podem serem observadas nos meses de maio, junho e dezembro para AN, LS e no mês de agosto para LS. No ano de 2006 a predominância foi de anomalias negativas de forte a intensa intensidade e as anomalias positivas em meses isolados de fraca intensidade, destacam-se que as incidências pluviais em ambos os municípios foram abaixo da média. O ano de 2010 caracterizado por ala variabilidades anômalas negativas e positivas ocasionadas pelas flutuações do fenômeno El Niño de intensidade fraca o qual auxiliou suas variabilidades pluviais em ambos os municípios de estudo, estas irregularidades são condizentes com os estudos de Marengo et al., (2008); Marengo et al., (2011).

Figura 12. Distribuições das anomalias anuais positivas e negativas no período de El Niño nos municípios Alagoa Nova e Lagoa Seca - Paraíba. 2005; 2006 e 2010.

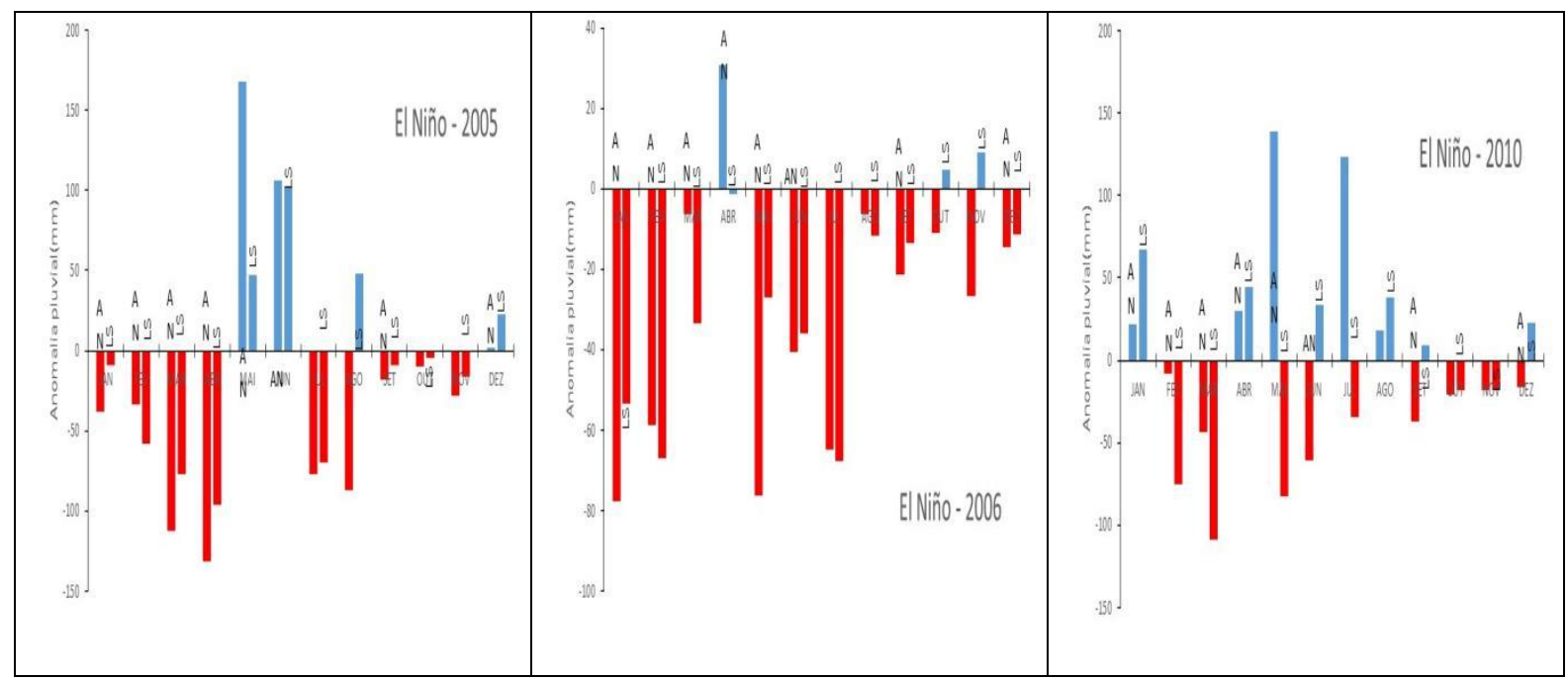

Fonte: Medeiros (2022).

O ano de 2012 caracterizado como El Niño registrou três meses de anomalias positivas (janeiro, fevereiro, junho) tendo como máxima anomalia o mês de junho e a mínimo fevereiro. Alagoa Nova registrou. Dois meses de anomalias positivas 
(outubro e novembro). As maiores anomalias negativas ocorreram para o mês de fevereiro em ambos os municípios em estudo, as menores anomalias negativas ocorreram no m mês de agosto para Alagoa Nova e outubro para Lagoa Seca, estas variabilidades não interferiram na produtividade da hortifruti e citricultura da área em debate.

Caracterizado por atuação do El Niño forte para o ano de 2013 onde se observa que para Alagoa Nova os meses de janeiro a março; junho a outubro ocorreu anomalias negativas e para Lagoa Seca os meses de abril, julho a dezembro a predominância foi de anomalias positivas, mesmo com um ano de El Niño forte as chuvas foram irregulares em ambos os municípios e estas irregularidades são condizentes com os estudos de Marengo et al., 2008 e Marengo et al., 2011.

Figura 13. Distribuições das anomalias anuais positivas e negativas no período de El Niño nos municípios Alagoa Nova e Lagoa Seca - Paraíba. 2012 e 2013.

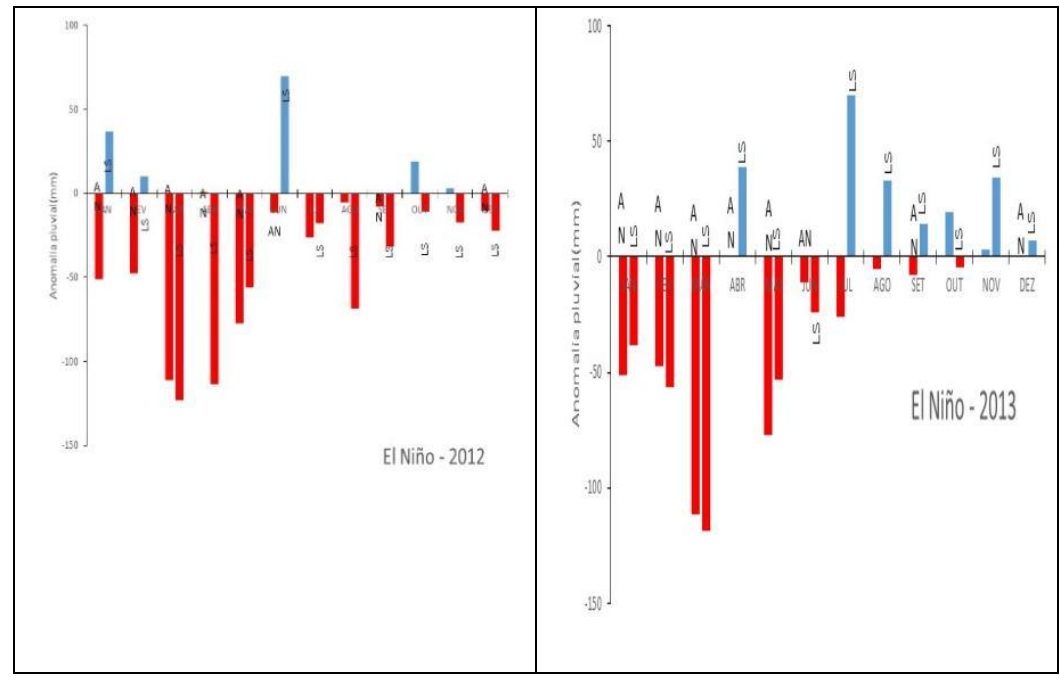

Fonte: Medeiros (2022).

As razões que explicam seu regime de precipitação do NEB, além de sua localização geográfica e extensão territorial é a combinação da Zona de Convergência Intertropical (ZCIT); processos de convecção organizada associados à Zona de Convergência do Atlântico Sul (ZCAS); eventos de Linhas de Instabilidade (LI); aquecimento ou resfriamento anômalo da temperatura da superfície do mar no Pacífico tropical, fenômenos conhecidos respectivamente como El Niño e La Niña (FISCH 1998). E nos últimos 10 anos, a configuração do Dipolo do Atlântico, vem afetando a distribuição da precipitação na bacia Amazônica (Alcântara, 2011; Marengo, 2009).

Este Ciclo Neutro foi considerado atípico, mais seco, por conta do sistema anômalo de alta pressão sobre o oceano Atlântico adjacente à região Sudeste, bloqueando a atuação dos sistemas frontais, favorecendo a manutenção do aquecimento oceânico através de incidência da radiação solar, desfavorecendo a formação Zona de Convergência do Atlântico Sul (Coelho et al., 2016).

\section{Conclusões}

Todavia, não se descartar que na maioria dos anos com anomalias negativas ocorreram de forma igualadas à fenômenos La Niña e ao El Niño, o contrário também pode ser registrado para o caso do El Niño que ocorreu anomalias negativa e na La Niña anomalias positivas ambos de intensidade aumentadas e/ou reduzidas. Portanto, nada se pode afirmar que nas regiões estudada os fenômenos ENOS não influenciaram em escalas menores ou maiores nos seus índices pluviais locais, e que o ENOS não são o principal elemento climático e/ou ambiental na região que contribui para a ocorrência de 
eventos extremos pluviais. Sendo necessário buscar avaliar outros fenômenos climáticos e o perfil ambiental dessa região para melhor justificar a variabilidade pluviométrica

A influência dos fatores locais na distribuição espacial da chuva é evidente nos gráficos de El Nina e La Nina, destacados pelas anomalias. A concentração pluviométrica é devida aos fatores controladores favoráveis, a saber, o relevo, a aproximação do planalto da Borborema e a vegetação. Em contrapartida, os acumulados mais baixos foram ocasionados pelo resfriamento da bacia do atlântico tropical e os bloqueios nos sistemas locais e regionais.

Os dados obtidos neste trabalho confirmaram a vocação dos municípios Alagoa Nova e Lagoa Seca nas atividades da citricultura e hortifruti voltada, mesmo que as influencias dos fenômenos adversos de El Niño e La Niña sejam ativos.

O resultado do estudo vem a contribuir para a geração de conhecimentos acerca da citricultura e hortifruti que como já advertido é de extrema importância para os municípios na parte socioeconômica e no bem-estar da população quando ocorrem períodos secos e chuvosos já mencionados em outros artigos.

\section{Referências}

Alcântara, C.R. (2011). Linha de instabilidade da Amazônia: estudo de caso e importância das características do perfil do vento na sua formação e desenvolvimento. Ciência \& Natura, 33(2), 197-226.

Araújo, P.H.C.; Cunha, D.A.; Lima, J.E. \& Féres, J.G. (2013). Efeitos da seca sobre a produtividade agrícola dos municípios do Nordeste. In: IX Encontro de Economia baiana, 2013, Salvador- BA. Anais. Economia baiana, Salvador, 151-117.

Araújo Gonzalez, R.; Andreoli, R.V.; Candido, L.A.; Kayano, M.T. \& Souza, R.A.F.A. Influência do evento El Niño - Oscilação Sul e Atlântico Equatorial na precipitação sobre as regiões norte e nordeste da América do Sul. Acta Amazonica, 43.4:469\{480, 2013. DOI: 10.1590/S0044-59672013000400009.

Azevedo, P.V.; Silva, F.D.S. (2007). Risco climático para o cultivo do algodoeiro na região Nordeste do Brasil. Revista Brasileira de Meteorologia, v. 22, n. 3, p. $408-416$

Cirino, P.H.; Féres, J.G.; Braga, M. J. \& Reis, E. (2015). Assessing the Impacts of ENSO - related Weather Effects on the Brazilian Agriculture. Procedia Economics and Finance, v. 24, n. 15, 146-155.

Clemente, C.M.S. (2021). Serviços ambientais e valoração dos estoques de carbono no semiárido baiano. 2021.195 p. Tese (Doutorado em Geografia Tratamento da Informação Espacial). Pontifícia Universidade Católica de Minas Gerais. Belo Horizonte.

Coelho, C.A.S.; Cardoso, D.H.F. \& Firpo, M.A.F. (2016). A seca de 2013 a 2015 na região sudeste do Brasil. Revista Climanálise, Edição Comemorativa de 30 anos do Climanálise, p. $55-61$.

Bodas Terassi, P.M.; Oliveira-Júnior, J.F.; De Góis, G. \& Galvani, E. Variabilidade do índice de precipitação padronizada na região norte do Estado do Paraná associada aos eventos de El Niño-Oscilação Sul. Revista Brasileira de Meteorologia, 33.1:11\{25, 2018, DOI: 10.1590/0102-7786331002

Depiné, H.; Castro, N.M.R.; Pinheiro \& A; Pedro, O. (2014). Preenchimento de falhas de dados horários de precipitação utilizando redes neurais artificiais. Revista Brasileira de Recursos Hídricos, 19(1),51-63.

FAO (2021). Alerta sobre degradação de um terço dos solos do planeta. Revista Tempo de aprender em Clima de Ensinar. Informativo 275.

Fisch, G.; Marengo, J.A.; Nobre, C.A. (1998). Uma revisão geral sobre o clima da Amazônia. Acta Amazônica, 22(2), 101-126.

Freire, J.L.M.; Lima, J.R.A. \& Cavalcante, E.P. (2011). Análise de Aspectos Meteorológicos sobre o Nordeste do Brasil em Anos de El Niño e La Niña. Revista Brasileira de Geografia Física, v. 04, n. 03, p. 429-444.

Grimm, A.M.; Barros, V.R. \& Doyle, M.E. (2000). Climate variability in Southern South America Associated with El Niño and La Niña Events. The Journal of Climate, v. 13 , n. 1 , p. $35-58$, janeiro.

Grimm, A.M.: Tedeschi, R.G. ENSO and extreme rainfall events in South America. Journal of Climate, v. 22, p.

Lazinski, L.R. - Variabilidade da utilização do modelo Soygro para a região de Londrina, PR. Dissertação (Mestrado), Escola Superior de Agricultura "Luiz de Queiroz”, Universidade de São Paulo, 1993. Piracicaba/SP.

Matzenauer, R.; Radin, B. \& Maluf, J.R.T. O fenômeno ENOS e o regime de chuvas no Rio Grande do Sul, Agrometeoros, 25.2:323-331, 2017. DOI: 10.31062/agrom.v25i2.25510 Mendonça, F.; Danni-Oliveira, I.M. El Niño e La Niña. In: Mendonça, F.; Danni-Oliveira, I. M. (org.).

Climatologia Noções básicas e climas do Brasil. São Paulo: Oficina de Textos, 2007. cap. 7.2, p. 189 - 193. ISBN 978-85-86238-54-3.

Marengo, J.A. (2008). Vulnerabilidade, impactos e adaptação à mudança do clima no semi-árido do Brasil. Parcerias Estratégicas, Brasília, v. 13, n. 27, p. 149$11589-1609,2009.76$. 
Research, Society and Development, v. 11, n. 3, e32311326608, 2022

(CC BY 4.0) | ISSN 2525-3409 | DOI: http://dx.doi.org/10.33448/rsd-v11i3.26608

Marengo, J.A. et al. (2011). Variabilidade e mudanças climáticas no semiárido brasileiro. In: Recursos hídricos em regiões áridas e semiáridas, v. 1, Campina Grande, PB: INSA, p. 383- 416

Marengo, J.A. (2009). Long-term trends and cycles in the hydrometeorology of the Amazon basin since the late 1920s. Hydrological Processes, 23(22), 32363244 .

Marengo, J.A.; Cunha, A.P.M.A. \& Alves, L.M. (2016). A Seca de 2012-15 no Semiárido do Nordeste do Brasil no Contexto Histórico. Revista Climanálise, v. 04, p. 49-54-54.

Medeiros, R.M.; Azevedo, P.V. \& Saboya, L.M.F. (2013). Classificação climática e zoneamento agroclimático para o município de Amarante - PI. Revista Brasileira de Agricultura Irrigada. 7, 170 - 180.

Molina, S.K.M.; Almeida, I.K.; Steffen, J.L. \& Sobrinho, T.A. (2014). Caracterização de disponibilidade hídrica e comparação de metodologias de regionalização de vazões. Geociências (São Paulo), 33(3), 506-515.

Nóbrega, R.S.; Santiago, G.A.C.F. \& Soares, D.B. (2016). Tendências do controle climático oceânico sob a variabilidade temporal da precipitação no nordeste do Brasil (Control Trends Oceanic Climate Under Temporary Variability of Rainfall in Northeast Brazil). Revista Brasileira de Climatologia, v. 18, p. 9-26.

Rebouças, A.C. Água na região Nordeste: desperdício e escassez. Estudos avançados, v. 11, n. 29, p. 127-154, 1997.

Silva, V.P.R. et al. (2011). Análise da pluviometria e dias chuvosos na região Nordeste do Brasil. Revista Brasileira de Engenharia Agrícola e Ambiental. v.15, n.2, p.131-138.

Silva, L. L.; Costa, R. F.; Campos, J.H.B.C. \& Dantas, R.T. (2009). Influência das precipitações na produtividade agrícola da Paraíba. Revista brasileira de Engenharia Agrícola e Ambiental, Campina Grande, 13(4), 454-461.

Silva, V.P.; Medeiros, R.M. \& Gomes Filho, M.F. (2006). Flutuação da precipitação em Alagoa Nova, Paraíba, em anos de "El Niño". II Workshop Internacional sobre água no semiárido brasileiro.

Silva, R.O.B.; Montenegro, S.M.G.L. \& Souza, W.M. (2017). Tendências de mudanças climáticas na precipitação pluviométrica nas bacias hidrográficas do estado de Pernambuco. Eng. Sanitária e Ambiental, 22(3), 579- 589.

Tucci, C.E.M. (2000). Água no Meio Urbano. In: Rebouças, A.; Braga, B.; Tundisi, J. G. (ed.) Águas Doces do Brasil: capital ecológico, uso e conservação. 2 ed. São Paulo: Escrituras Editora Distribuidora de Livros, p.475-508.

Yan, G.; Liu, Y.; Chen, X. (2018). Evaluating satellite-based precipitation products in monitoring drought events in southwest China. International Journal of Remote Sensing, 39(10), 3186-3214. 